\title{
Research on Optimal Adjustment Test for SCR Denitrification System in Coal-fired Power Plant
}

\author{
Ke LIU* \\ State Grid Shandong Electric Power Research Institute \\ Jinan 250003, China \\ e-mail: luliuke@163.com \\ Hai-chao WANG \\ State Grid Shandong Electric Power Research Institute \\ Jinan 250003, China \\ Fan-jun HOU \\ State Grid Shandong Electric Power Research Institute \\ Jinan 250003, China
}

\begin{abstract}
We present an effective optimal adjustment test method for SCR denitrification device. The decrease of catalyst activity in local regions can lead to non-uniformity of NOx concentration and augmentation of slipped ammonia around outlet of SCR device. In this case, we introduce a two-step adaptive adjustment method to minimize the concentration of slipped ammonia meanwhile ensures the NOx emission concentration around outlet of SCR within standard range.
\end{abstract}

Keywords- SCR; Denitrification system; Adjustment test; Ammonia escape.

\section{INTRODUCTION}

With the improvement of industrial emissions standards, a large number of denitrification transformation works is carried out in most coal-fired power plants in China. The Selective Catalytic Reduction (SCR) is one of the most widely used and relatively mature flue gas denitrification methods.

The principle of SCR is based on catalytic reduction between ammonia and NOx. With the help of the catalyst, ammonia was injected into the flue gas to catalytically reduce $\mathrm{NOx}$ to $\mathrm{N} 2$ and $\mathrm{H} 2 \mathrm{O}$. Due to the uneven distribution of the flue gas' density and flow velocity, the injected ammonia and flue gas cannot be mixed completely. In some regions, ammonia is relatively surplus, the so-called ammonia escape phenomenon occurs [1][2]. Under certain conditions, the slipped ammonia reacts with $\mathrm{H} 2 \mathrm{O}$ and $\mathrm{SO} 3$ in the flue gas to form NH4HSO4, which is a highly viscous and corrosive substance in liquid state. It can stick on the denitration reactor and downstream equipment, and leads to terrible blockage and corrosion. The greater the concentration of ammonia and $\mathrm{SO} 3$ is, the higher initial formation temperature for $\mathrm{NH} 4 \mathrm{HSO} 4$. When the temperature is lower than the initial formation temperature, the formation reaction of NH4HSO4 occurs [3][4]. According to the research of RICHARD. T. W [5], the initial formation

\author{
Meng ZHANG \\ State Grid Shandong Electric Power Research Institute \\ Jinan 250003, China \\ Li-meng ZHANG \\ State Grid Shandong Electric Power Research Institute \\ Jinan 250003, China \\ Qing-chuan ZHAO \\ State Grid Shandong Electric Power Research Institute \\ Jinan 250003, China
}

temperature for the typical low sulfur coal and medium sulfur coal is $200-220^{\circ} \mathrm{C}$.In the middle and low temperature range of the air pre-heater, the flue gas temperature is lower than the initial formation temperature, the NH4HSO4 could be formed. The produced $\mathrm{NH} 4 \mathrm{HSO} 4$ adheres to the heating surface of the air pre-heater, lead to increase the air preheater' $\mathrm{s}$ resistance, reduce heat transfer efficiency, etc. Large amount of slipped ammonia can even lead to blockage of air pre-heater. Therefore, the ammonia spray optimization test is introduced, which can optimize the ammonia's distribution in denitrification system, and reduce the total amount of slipped ammonia. The test is of great significance for the safe operation of downstream equipment and unit energy saving [6][7].

\section{THE AMMONIA SPRAY OPTIMIZATION TEST}

According to the principle of SCR, the amount of ammonia sprayed should match the NOx concentration in each region of the flue. While in actual practice, the amount of ammonia sprayed cannot be fully matched with the NOx in perfect reaction ratio in each region due to uneven distribution of gas composition and flow velocity. By adjusting the ammonia quantity of each injection branch in the inlet of SRC, the uniformity of $\mathrm{NOx}$ and $\mathrm{NH} 3$ distribution at the outlet of the SCR is improved and the amount of slipped ammonia is reduced.

The test method is as follows. First, measure the NOx and $\mathrm{NH} 3$ distribution in each region of the denitrator. Then adjust the amount of ammonia sprayed in the corresponding region until the distribution of NOx and NH3 in each region is uniform. The adjustment process is realized by increasing the amount of ammonia injection in the region with higher NOx concentration at the outlet of the denitrator, and reducing the amount of ammonia injection in the region with higher NH3 concentration at the outlet of the denitrator. In case of NOx at the outlet is not exceeded, the amount of ammonia sprayed in each region and the maximum value 
sprayed depends on the concentration of NOx and NH3 around each outlet respectively.

Regional good catalyst activity is an important factor to ensure the effectiveness. In some cases, we augment the amount of ammonia sprayed in a region; the concentration of NOx is not reduced significantly, while the concentration of NH3 changes in the opposite direction. This phenomenon indicates that denitration reaction in the region has reached the limit of adjustment. The activity of the catalyst in this region should be tested. We will explain the phenomenon in the next section.

\section{AMMONIA SPRAY OPTIMIZATION TEST IN A POWER PLANT}

\section{A. Equipment Overview}

The ammonia spray grid is placed upstream of the SCR reactor in \#4 unit of a certain power plant. The flue gas from the economizer is mixed with ammonia, and then enters into actor A, B respectively. Each reactor is equipped with two honeycomb catalyst layers. The flue gas flows vertically downward. The inlet and outlet sections of the reactor are equipped with baffles to ensure the uniformity of flue gas velocity field. The reinforcing plates and brackets inside the reactor should be designed to prevent fouling, and compensation measures for thermal expansion should be taken into consideration. The SCR reactor catalyst consists of three parts, including two initial layers and one preparatory layer. The spray ammonia system consists of a header and a branch pipe. Each branch pipe includes a flow control valve, an orifice, and a pressure gauge. The system has a total of 15 control valve and 540 nozzles. The gas supply header is equipped with a pressure indicator. Figure 1 shows spray ammonia on-site layout respectively.

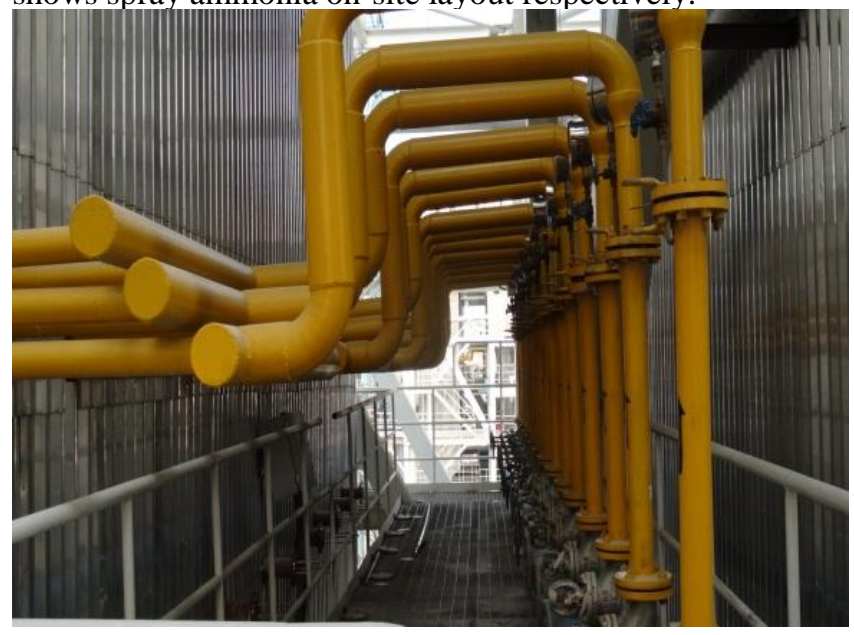

Figure 1. Spray ammonia on-site layout

\section{B. Test Method and Process}

- The grope test for denitrification device is taken under the 250MW unit load conditions. The distribution of NOx and $\mathrm{O}_{2}$ around inlet and outlet of the denitrator is measured by multi-point grid sampling method with flue gas sampling guns. The concentration of escaped ammonia is measured by chemical adsorption method. The outlet measurement points are located at the reactor outlet, around the top of level flue. There are 9 measurement points at the $\mathrm{A}$ and $\mathrm{B}$ side respectively. We number $\mathrm{A} 1$ to $\mathrm{A} 9, \mathrm{~B} 1$ to $\mathrm{B} 9$ in order from the outside to the inside of the reactor respectively.

- The optimization experiment of ammonia injection is carried out according to the NOx distribution around the outlet. The adjustment effect is determined by the deviation coefficient $\mathrm{Cv}$ of the NOx concentration around the outlet. When $\mathrm{Cv}<20 \%$, the adjustment is completed. Then the denitrification efficiency test and the escape ammonia concentration test are carried out.

- Verify the adjustment effect by carrying out the theNOx distribution test, the denitrification efficiency test and the slip ammonia concentration test under 250MW unit load conditions.

- The emission concentration of air pollutants in the standard oxygen content is calculated as in Eq. (1).

$$
C=C^{\prime} \times \frac{21-6}{21-O_{2}}
$$

Where:

$C$ : the emission concentration of air pollutants in the standard oxygen content, $\mathrm{mg} / \mathrm{m} 3$ or $\mu \mathrm{L} / \mathrm{L}$;

$C^{\prime}$ : the air pollutant emission concentration measured, $\mathrm{mg} / \mathrm{m} 3$ or $\mu \mathrm{L} / \mathrm{L}$;

O2: the Oxygen content measured, $\%$.

Denitration efficiency of denitration device is calculated according to formula (2)

$$
\eta_{N O_{x}}=\frac{C_{N O_{x i}}-C_{N O_{x o}}}{C_{N O_{x i}}} \times 100
$$

Where:

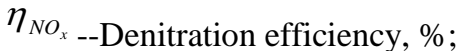

$N O_{x i}$--NOx concentration in the flue gas around inlet, $\mathrm{mg} / \mathrm{Nm} 3$;

$N O_{x o}$--NOx concentration in the flue gas around outlet, $\mathrm{mg} / \mathrm{Nm} 3$;

The deviation coefficient $\mathrm{Cv}$ is calculated according to formula (3): 


$$
\begin{gathered}
\sigma=\sqrt{\frac{1}{(n-1)} \sum_{i=1}^{n}\left(x_{i}-\bar{x}\right)^{2}} \\
\bar{X}=\frac{1}{n} \sum_{i=1}^{n} x_{i}
\end{gathered}
$$

Where

$X_{i}$-- NOx concentration at a certain point around outlet;

$\sigma$--the standard deviation of NOx concentration around outlet;

$\bar{X}$--The mean value of NOx emission concentration at all measuring points of the outlet section of the denitrator.

\section{Test Results and Analysis}

From the results of grope test, the $\mathrm{Cv}$ of NOx around $\mathrm{A}$ side outlet is $27.90 \%$, and is $21.34 \%$ around B side outlet. The concentration of slip ammonia around A and B side is $19.22 \mathrm{ppm}$ and $8.2 \mathrm{ppm}$ respectively. All related indicators are shown in Tab. 1.

TABLE I. INDICATOR MEASUREMENTS RESULTS OF SCR DEVICE BEFORE ADJUSTMENT

\begin{tabular}{llll}
\hline Performance indicators & Unit & A side & B side \\
\hline Amount of sprayed ammonia & $\mathrm{kg} / \mathrm{h}$ & 60.80 & 72.03 \\
Average NOx concentration around inlet & $\mathrm{mg} / \mathrm{m}^{3}$ & 404.54 & 395.42 \\
Average NOx concentration around inlet & $\mathrm{mg} / \mathrm{m}^{3}$ & 118.98 & 110.48 \\
$\begin{array}{l}\text { Distribution deviation coefficient of NOx } \\
\text { around outlet (Cv) }\end{array}$ & $\%$ & 27.9 & 21.34 \\
$\begin{array}{l}\text { Average concentration of escape ammonia } \\
\text { under reference oxygen }\end{array}$ & $\mathrm{ppm}$ & 19.22 & 8.2 \\
$\begin{array}{l}\text { Denitrification efficiency } \\
\text { Average NOx concentration around inlet }\end{array}$ & $\mathrm{mg} / \mathrm{m}^{3}$ & 118.98 & 110.48 \\
\hline
\end{tabular}

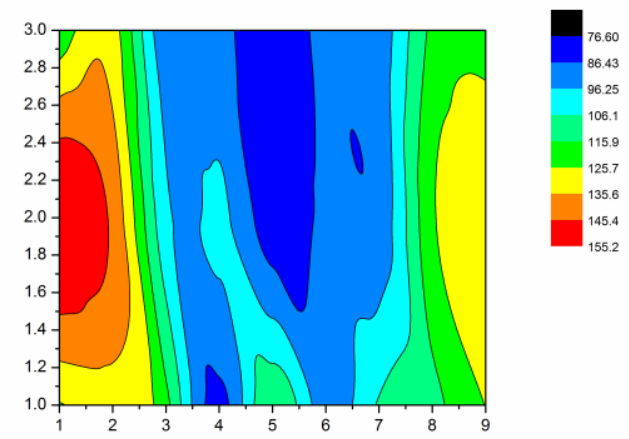

Figure 2. TheNOx concentration distribution around A side outlet after preliminary adjustment

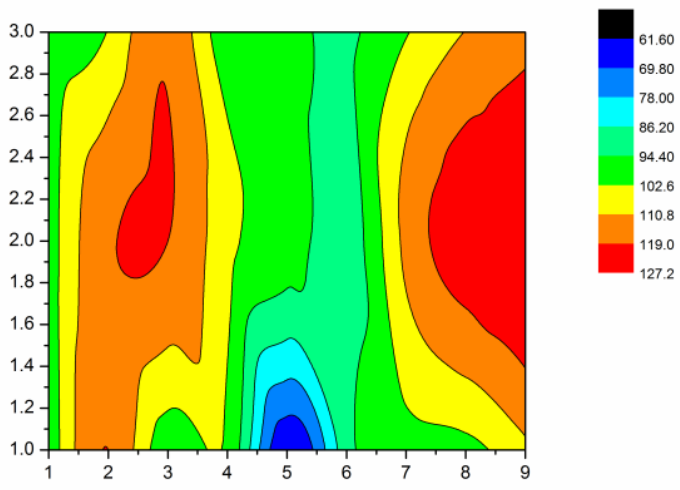

Figure 3. TheNOx concentration distribution around B side outlet after preliminary adjustment

Adjust the regulating butterfly valves of each AIG ammonia spraying branch according to the distribution of NOx around SCR outlet. The test results after repeated measurements and adjustments are shown in Fig.2 and Fig.3. The $\mathrm{Cv}$ of NOx around A, B side outlet reduce to $21.63 \%$ and $13.35 \%$ respectively. The uniformity of NOx distribution around SCR outlet is improved.

The concentration of escaped ammonia is measured, shown in Tab. 2

TABLE II. THE CONCENTRATION OF ESCAPED AMMONIA MEASURED AROUND SCR OUTLET

\begin{tabular}{lllllllllll}
\hline Measurement position & 1 & 2 & 3 & 4 & 5 & 6 & 7 & 8 & 9 & AVE \\
& & & & & & & & & & \\
\hline $\mathrm{NH}_{3}(\mathrm{ppm}) \mathrm{A}$ side & $12.137 .806 .51 /$ & $6.16 /$ & $5.50 /$ & 5.897 .33 \\
$\mathrm{NH}_{3}$ (ppm)B side & 4.37 & $6.55 /$ & $9.35 /$ & 3.635 .293 .065 .385 .38
\end{tabular}

The slipped ammonia concentration at A1 point reaches $12.13 \mathrm{ppm}$, and the emission concentration of NOx at this point even reaches $155 \mathrm{mg} / \mathrm{m} 3$ (see fig. 2 ), which greatly exceed the $100 \mathrm{mg} / \mathrm{m} 3$ emission standards. In order to reduce the NOx emission in that region, we augment the amount of spray ammonia at the corresponding spray tube. The results is shown in Tab. 3.

TABLE III. CONCENTRATION CHANGES AFTER AUGMENTATION OF SPRAY AMMONIA AMOUNT

\begin{tabular}{lll}
\hline & Before regulation & After regulation \\
\hline $\mathrm{NOx}\left(\mathrm{mg} / \mathrm{m}^{3}\right), \mathrm{A} 1$ & 155 & 150 \\
$\mathrm{NH}_{3}(\mathrm{ppm}), \mathrm{A} 1$ & 12.13 & 16.36 \\
\hline
\end{tabular}

Results shown that, the concentration of NOx emission is not significantly reduced, while the slipped ammonia around the region augment obviously, which indicates that the catalytic activity in this region has been greatly reduced. In this case, the right approach is to appropriately reduce the amount of ammonia injection.

Further adjustments are carried out under the principle above. The results are shown in Fig $4-5$ and Table 4 


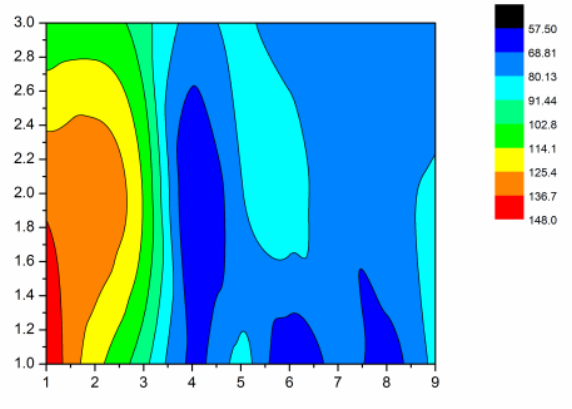

Figure 4. TheNOx concentration distribution around A side outlet after further adjustment

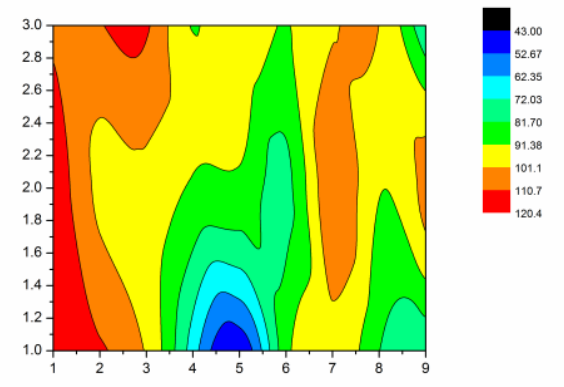

Figure 5. TheNOx concentration distribution around B side outlet after further adjustment

TABLE IV. INDICATOR MEASUREMENTS RESULTS OF SCR DEVICE AFTER FURTHER ADJUSTMENT

\begin{tabular}{llcc}
\hline Performance indicators & Unit & A side & B side \\
\hline Amount of sprayed ammonia & $\mathrm{kg} / \mathrm{h}$ & 37.2 & 46.6 \\
Average NOx concentration around inlet & $\mathrm{mg} / \mathrm{m}$ & 368.23 & 384.03 \\
Average NOx concentration around inlet & $\mathrm{mg} / \mathrm{m}$ & 80.21 & 87.57 \\
$\begin{array}{l}\text { Distribution deviation coefficient of NOx } \\
\text { around outlet (Cv) }\end{array}$ & $\%$ & 23.72 & 19.91 \\
$\begin{array}{l}\text { Average concentration of escape ammonia } \\
\text { under reference oxygen }\end{array}$ & $\mathrm{ppm}$ & 3.42 & 2.35 \\
$\begin{array}{l}\text { Denitrification efficiency } \\
\text { Average NOx concentration around inlet }\end{array}$ & $\mathrm{mg} / \mathrm{m}$ & 37.2 & 46.97 \\
\hline
\end{tabular}

From the results above, we can see that the although the distribution deviation coefficient of NOx is slightly increased than that of the preliminary adjustment, the concentration of escaped ammonia around SCR outlet is well controlled, the amount of spray ammonia is reduced significantly, and the safe and economic operation of downstream equipment is guaranteed.

\section{CONCLUSION}

The distribution of flow rate, soot and NOx in flue gas is rarely even. After a period of operation, the flue denitration catalyst activity appears inconsistent and its activity reduced significantly in certain region. In this case, it is inappropriate to simply use the NOx concentration distribution around the denitrification unit outlet as the optimal adjustment index. The right approach is to appropriately reduce the amount of ammonia injection according to the amount of spraying ammonia in the related region. If it is difficult to ensure the overall NOx emission level, replacement of the localized catalyst should be considered.

In this paper, the decrease of local catalytic activity is not a single case, and its treatment method has certain reference value for other similar tests.

\section{REFERENCES}

[1] Z. Lin, W. Bijun, et al. Production and Application of SCR flue gas denitration catalyst, J. China Electric Power.2009,42(8): 61-64.

[2] C. Zhiyong, T. Chengjun, et al.. Optimal Regulation Test of Ammonia Spraying on SCR Flue Gas Denitrification System in Coal - fired Boiler,J.China Electric Power. 2011, 44(11): 55-58.

[3] M. Shuangzhen, J. Xin, et al. Formation Mechanism and Control of Hydrogen Ammonium Sulfate in SCR Flue Gas DenitrificationProcess,J. Thermal Power Generation. 2010,39(8):1216.

[4] RICHARD T W, THOMAS L W. SCR ammonia slip distribution in coal plant effluents and dependence upon $\mathrm{SO}_{3}, J$. Power Plant chemistry.2004, 6(5):295-304.

[5] D. Jianxun, L. Chenfei, et al. Simulation of the Effect of Non-uniform Distribution of Reducing Agent on Denitrification Performance of SCR.J.Power System Engineering. 2007, 23(1): 20-24.

[6] L. Yongjin, X.Chenhong, et al. Research on SCR flue gas denifitrication device optimal operation at coal-fired power plant, $J$. Boiler Technology. 2008, 39(5): 60-63.

[7] JERMY J S, WANG Shuxiao, HAO Jiming. Design and Operational Considerations for Selective Catalytic Reduction Technologies at Coal-fired Boilers.J. Energy. 2012, 6(1): 98-105. 